\title{
Separating the role of biotic interactions and climate in determining adaptive response of plants to climate change
}

\author{
Sara Tomiolo, ${ }^{1,4}$ Wim H. van der Putten, ${ }^{2,3}$ and Katja Tielbörger ${ }^{1}$ \\ ${ }^{1}$ Institute of Ecology and Evolution, Plant Ecology Group, University of Tübingen, D-72076 Tübingen, Germany \\ ${ }^{2}$ Department of Terrestrial Ecology, Netherlands Institute of Ecology (NIOO-KNAW), P.O. Box 50, 6700 AB Wageningen, \\ The Netherlands \\ ${ }^{3}$ Laboratory of Nematology, Wageningen University and Research Centre, P.O. Box 8123, 6700 ES Wageningen, The Netherlands
}

\begin{abstract}
Altered rainfall regimes will greatly affect the response of plant species to climate change. However, little is known about how direct effects of changing precipitation on plant performance may depend on other abiotic factors and biotic interactions. We used reciprocal transplants between climatically very different sites with simultaneous manipulation of soil, plant population origin, and neighbor conditions to evaluate local adaptation and possible adaptive response of four Eastern Mediterranean annual plant species to climate change. The effect of site on plant performance was negligible, but soil origin had a strong effect on fecundity, most likely due to differential water retaining ability. Competition by neighbors strongly reduced fitness.

We separated the effects of the abiotic and biotic soil properties on plant performance by repeating the field experiment in a greenhouse under homogenous environmental conditions and including a soil biota manipulation treatment. As in the field, plant performance differed among soil origins and neighbor treatments. Moreover, we found plant species-specific responses to soil biota that may be best explained by the differential sensitivity to negative and positive soil biota effects. Overall, under the conditions of our experiment with two contrasting sites, biotic interactions had a strong effect on plant fitness that interacted with and eventually overrode climate. Because climate and biotic interactions covary, reciprocal transplants and climate gradient studies should consider soil biotic interactions and abiotic conditions when evaluating climate change effects on plant performance.
\end{abstract}

Key words: biotic interactions; climate change; competition; plant-plant interactions; plant-soil-biota interactions; reciprocal transplants.

\section{INTRODUCTION}

Climate change is supposed to have profound consequences for the performance and persistence of plant and animal species. Therefore, the possibility for species to survive in situ under changed conditions hinges on their ability to adapt (Walther et al. 2002, Davis et al. 2005). A growing body of literature suggests that the response of plants to climate change is not only a function of climate itself, but that abiotic and biotic environmental conditions might affect the magnitude and direction of such response (Tylianakis et al. 2008, Gilman et al. 2010, Lau and Lennon 2011). Therefore, models should include information about local adaptation (Schiffers et al. 2013) and the potential of species to evolve (Thuiller et al. 2013). This means that the realized distribution of a species should be interpreted as a function of not only climate (Turesson 1930), but also other abiotic variables and biotic interactions between individuals from the same (Brooker and Callaghan

Manuscript received 29 July 2014; revised 11 September 2014; accepted 17 September 2014. Corresponding Editor: S. D. Allison.

${ }^{4}$ E-mail: sara.tomiolo@gmail.com
1998) or different trophic levels (Lavergne et al. 2010, van der Putten et al. 2010).

A possible field approach to test current and potentially future adaptation of plants to climate is represented by reciprocal transplants of seed origins from different habitats under contrasting climatic regimes (Sundqvist et al. 2013), and comparison of their performance in "home" and "away" conditions (Galen et al. 1991, Linhart and Grant 1996, Wardle and Jonsson 2013). The assumption is that each seed origin has evolved adaptations to best perform in their local climate (Galloway and Fenster 2000). However, if local adaptation is narrow, the potential to adapt to a changing climate is limited. Therefore, growing genotypes under local and non-local climate and assessing their performance in home and away-from-home conditions, allows for investigating whether or not a population may persist under predicted scenarios of climate change. So far, remarkably few studies investigated the role of plant-plant interactions (Klanderud 2005, Ariza and Tielbörger 2011) and plant-soil-biota interactions (Link et al. 2003, De Long et al. 2014) in a climate change context, and even fewer have applied evolutionary approaches such as reciprocal transplants 
(Macel et al. 2007, Lau and Lennon 2011). Due to the scarce literature on the interactive effects of biotic interactions and abiotic factors on plant performance or local adaptation (Casper and Castelli 2007, Shannon et al. 2012), there is very little knowledge on how changes in the abiotic environment (e.g., rainfall and soil) may interact with biotic interactions to affect plant adaptive potential to climate change (Schweiger et al. 2010, Ortegon-Campos et al. 2012). The paucity of information in the field is partly due to the practical difficulties of combining numerous factors together in a meaningful experiment; among those are the different rates at which above- and belowground communities react to changes (van der Putten et al. 2009).

Ecological theory suggests that intensity and direction of biotic interactions and, consequently, plant performance change according to the level of stress (Callaway and Walker 1997). However, the degree to which such changes are predictable is still debated (e.g., Maestre et al. 2009). A common assumption is that competition between plants prevails at the favorable end of an ecological gradient and facilitation dominates at the stressful end (Bertness and Callaway 1994, Brooker and Callaghan 1998, He et al. 2013). Thus, depending on whether or not climate change is expected to aggravate abiotic stress, there might be either an increased dependence on positive interactions, or an increased probability of competitive exclusion. Similarly, studies have shown that plant-soil-biota interactions can vary from negative to positive according to the level of productivity. For example, negative soil effects are associated to relatively high productivity and dense plant communities, because plants growing under these conditions are more susceptible to pathogens (Thrall et al. 2007, Kulmatiski et al. 2012). Conversely, positive effects of soil biota on plant performance are expected to be more common in unproductive soils with sparse plant cover (Reynolds et al. 2003) and sparse soil biota (Thrall et al. 2007). Therefore, based on previous studies (Reynolds et al. 2003, Neuhauser and Fargione 2004, Thrall et al. 2007, Schweitzer et al. 2008, Lau and Lennon 2011) we may expect that in productive environments the soil community will reduce host fitness. In such cases, when transplanted, plant ecotypes would experience an away-from-home soil advantage that has nothing to do with climatic conditions. Equally, ecotypes from less productive environments are likely to experience a home-soil advantage because they benefit from symbiotic mutualists, such as arbuscular mycorrhizal fungi. Such responses may be, at least to some extent, species specific, because some plant families depend much less on positive soil effects, e.g., absence of mycorrhizal fungi in Cruciferae (Newman and Reddell 1987), or because of specificity of the symbionts (Klironomos 2003).

To our knowledge, no study has attempted to disentangle the combined effect of climate, neighbors, soil biotic and abiotic properties on plant fitness for evaluating response to climate change. Therefore, our ability of predicting potentially adaptive responses of plants to climate change is still limited. Also, reciprocal transplants have rarely combined manipulation of several biotic and abiotic factors for disentangling their relative importance for local adaptation. With our study, we attempted to separate the effects of abiotic factors (rainfall and soil) and biotic interactions (plantplant and plant-soil-biota interactions) on plant performance. We used Eastern Mediterranean annual plant communities that are of great conservation concern due to high species richness and high vulnerability to climate change (Sala et al. 2000), and because they are relatively easy to manipulate.

We studied communities in two climatically contrasting sites where water is the main limiting factor and plants are highly responsive to rainfall variation. A third site, much drier than the other two, was initially included in the study but subsequently dropped due to an extreme drought. These sites are relevant for climate change studies because regional climate scenarios suggest a high probability for decreasing precipitation (Smiatek et al. 2011). According to such scenarios, sites previously experiencing a Mediterranean climate will likely experience a semiarid climate with high interannual variability in precipitation. As such, the transition zone between Mediterranean and semiarid conditions is where the strongest climate effects on vegetation are expected (Sternberg et al. 2011). Furthermore, this region is under strong human pressure (Tielbörger et al. 2010), so that the impact of climate change might be magnified by high water use for agriculture and livestock.

For our experiment, we used four target species that are characterized by a wide distribution range and display ecotypic differentiation with respect to rainfall availability (Petrů and Tielbörger 2008, Tielbörger et al. 2012). We tested the hypotheses that (1) plants perform better under home site conditions, irrespective of biotic interactions; (2) the presence of neighbors reduces plant fitness most under favorable climatic conditions (i.e., wetter climates) because of increased competition; (3) plants from productive environments perform better in away-from-home soil, as opposed to plants from unproductive environments that perform better in home soil; (4) the effect of soil biota in productive soil origins reduces plant performance more than in less productive soil origins.

\section{Material and Methods}

The study was performed at three sites along a steep north-south climatic gradient in Israel. The sites are located on calcareous bedrock and southern aspect. Although similar in elevation and mean annual temperatures, they differ significantly in annual rainfall, vegetation and soil as described in Holzapfel et al. (2006). The northern site (M) is characterized by Mediterranean climate, with roughly twice the annual 
rainfall $(550 \mathrm{~mm})$ than that at the semiarid (SA, 270 $\mathrm{mm})$ site, and the arid (A, $90 \mathrm{~mm}$ ) site is very dry with desert climate (see Appendix A: Table A1). Unfortunately, a severe drought led to almost complete mortality of plants at the arid site, and we needed to focus on the two remaining sites. However, their difference in rainfall is still large and greater than the $25 \%$ reduction predicted under some climate change scenarios, allowing us to observe responses to relatively extreme changes in climate. The field study was carried out during the growth season 2010-2011, a relatively dry year, with the M and SA sites receiving $66 \%$ and $60 \%$ of their long-term average rainfall, respectively (Appendix A: Table A1).

Mediterranean soil texture is characterized by a higher proportion of clay (Zwikel et al. 2007) and deeper soils, which result in higher water-holding capacity (Zwikel et al. 2007) and higher wilting point (Saxton et al. 1986) compared to semiarid soil. Namely, under dry conditions, the wilting point is reached more quickly in Mediterranean soil than in semiarid soil (Veihmeyer and Hendrickson 1949). Overall, the two soils developed over the same type of bedrock, topography and time since pedogenesis (Sternberg et al. 2011), but differ in terms of climate and soil biota (Oren and Steinberger 2008).

The vegetation is dominated by a community of winter annuals and scattered small shrubs with only partially overlapping species composition across sites (Tielbörger et al. 2014). This offers a unique potential for studying the response of different populations to climate. Annual plant cover is $60 \%$ at the $\mathrm{M}$ site and $10 \%$ at the SA site (Schiffers and Tielbörger 2006).

\section{Species}

We selected four native winter annuals that are widely distributed across Israel (Feinbrun-Dothan 1986), reach high abundance at both study sites and represent different taxonomic groups with potentially different response to biotic interactions. Biscutella didyma (L.) is a non-mycorrhizal crucifer (Newman and Reddell 1987); Urospermum picroides (L.) F.W. Schmidt is a composite, and Brachypodium distachyon (L.) P. Beauv. and Stipa capensis Thunb. are both Poaceae (FeinbrunDothan 1986). Ecotypic differentiation along this or a similar climate gradient has been demonstrated for $B i$. didyma (Petrů et al. 2006) and Br. distachyon (Liancourt and Tielbörger 2011)

\section{Field experiment}

To test for local adaptation to rainfall, neighbors, and soil properties, we set up a reciprocal seed-sowing and soil-transplant experiment between $M$ and SA sites, while removing neighbors manually where planned. At each site (see Plate 1) and for each species, we combined in a full factorial manner seed origin (M, $\mathrm{SA}$ ), soil origin (M, SA), and neighbors (presence, removal), resulting in eight treatment combinations per species that were replicated 10 times at each site (Appendix A: Fig. A1a).

In March-April 2010, we collected for each species seeds of 80 randomly chosen individuals from an area of approximately $250 \times 500 \mathrm{~m}$ at each site. At least 10 seeds per individual plant were collected and each seed family was bagged individually. In July 2010, we excavated 80 randomly selected plots (surface, $400 \mathrm{~cm}^{2}$; depth, $5 \mathrm{~cm}$ ) at each site by avoiding heavily disturbed areas, large rocks, and patches under shrubs, and keeping a minimum distance of $20 \mathrm{~cm}$ between plots. The distance among plots was chosen as to largely exceed distances over which plant roots can grow, such that possible interactions were mostly with the naturally surrounding plant community (Ariza and Tielbörger 2011). Soil removed from each site was pooled together and homogenized because small-scale heterogeneity in soil seed bank and plant abundance is substantial (Siewert and Tielbörger 2010; M. Sternberg, personal communication) and may mask subtle treatment effects. Previous studies showed that pathogens are unlikely to spread quickly through soil mixture (van der Putten et al. 1988), thus we were confident that harmful soil microorganism potentially present in isolated soil samples were highly diluted and thus unlikely to affect all the bulk soil taken from a site. Because the species pool is dominated by winter annuals that are stored as seeds in the soil seed bank during the dry season, both seeds and soil organisms were dormant (Noy-Meir 1973, Alon and Steinberger 1999) and could thus be transferred together with their soil without any damage to plants, seeds and soil organisms. The soil was stored in paper bags and kept in a net-house at the University of Rehovot, where the soil experienced abiotic conditions similar to those in the field. During September 2010, one-half of the plots at each site were selected randomly to be filled with $\mathrm{M}$ soil and the other half with SA soil. Thereafter, we sowed one-half of the plots with seeds from $\mathrm{M}$ origin and the other half with seeds from SA origins that had been stored under natural summer conditions.

Seeds of the four species were sown into equally sized quadrants in each plot. The position of the species within the plots was randomized and individual seed families (10 seeds each) were sown within a $5 \mathrm{~cm}$ diameter plastic ring to avoid secondary seed dispersal during the first major rainstorm (see Ariza and Tielbörger 2011). To prevent contamination from the surrounding environment, we covered the surface of the plots with a layer of organza, a see-through synthetic fabric (Appendix A: Fig. A1b) that was removed shortly after the first major rain. Previous experiments indicated that the organza cover neither inhibits germination nor alters the amount of water and light reaching the soil surface (Petrů and Tielbörger 2008).

We monitored germination of the first main cohort. After three weeks, when no more germination occurred, the plastic rings were carefully removed and all but one randomly chosen seedling, which served as the target for 
further observations, were removed as well. In the neighbor removal treatments, all individuals that emerged around the target from the soil seed bank were removed from the plots by cutting the base of the stem with a scalpel so as to avoid disturbance to the soil or the plant roots. As all neighbors were annuals, they died immediately after being cut. At the end of the reproductive season, the seeds produced by each target plant were collected. Seed production was chosen as response variable because it is unlikely to be influenced by maternal effects (Weiner et al. 1997) and it best correlates to fitness.

\section{Greenhouse experiment}

A greenhouse experiment, similar to the field set up, focused on disentangling the role of biotic interactions in determining plant fitness. While keeping watering conditions constant, plant and soil community manipulations were added (Appendix A: Fig. A1c). We applied to the full-factorial combination of species, seed origin (M, SA) and soil origin (M, SA), three community treatments comprising presence of neighbors and live soil, neighbor removal and live soil, and sterilized soil. Because the seed bank was inevitably destroyed during the sterilization process, there was no treatment combining sterilized soil and presence of neighbors. The full factorial combination of all factors resulted in 12 treatments that were replicated 12 times.

During August 2011, we excavated approximately 500 $\mathrm{kg}$ of soil from the two sites (M and SA) in Israel. Soil was sampled up to a depth of $10 \mathrm{~cm}$, and the top layer $(0-$ $3 \mathrm{~cm}$ ), which contained the seed bank, was kept separated from the soil from greater depth, which was used for filling the bottom of the pots. The soil, including the dormant seeds and soil organisms, was kept in a net house in Rehovot until the end of the summer in order to replicate the conditions experienced in the field, and then shipped to Germany in sealed containers.

During October and November 2011, the experiment was set up in a greenhouse at the University of Tübingen, Tübingen, Germany. To test the effect of the soil community, we sterilized one-third of the soil by autoclaving it at $121^{\circ} \mathrm{C}$ two times for a total of 6 hours, with a pause of 24 hours in between. Because of the known effects of sterilization treatments on soil composition and texture (McNamara et al. 2003) we conducted chemical and textural analyses on our soils before and after sterilization (Appendix B: Table B1). These indicated no unwanted side effect of the sterilization treatment. For neighbor removal treatments, we removed individuals emerging from the soil seed bank upon germination.

Pots of $10 \times 10 \times 10 \mathrm{~cm}$ were filled with soil and sown with single maternal families of each species. Individual families (five seeds per family) of each species were sown within a plastic ring. The pots were placed $10 \mathrm{~cm}$ apart in order to avoid any interaction between plants of different treatments, and were periodically randomized throughout the entire experiment. In November 2011, all pots were watered to saturation and germination was monitored.
As in the field, single target individuals for each pot were randomly selected once germination was complete. For the entire duration of the experiment, plants were watered to saturation, and temperature was kept at values consistent with the averages expected in the field.

\section{Statistics}

To analyze the effects of abiotic and biotic factors on the response variable, seed production, we applied generalized linear models (GLM) with Poisson distribution and log link function for each species separately.

To analyze the data from the field experiment we used site (i.e., rainfall), seed origin, soil origin, and neighbor treatments as independent variables. We applied full factorial models in order to test our predictions and also to look for other potentially relevant interactions. In analyzing the data from the greenhouse experiment, we tested the effect of seed origin, soil origin, neighbors, and soil community treatments on seed production. The database was split in two subsets in order to use an even number of contrasts when comparing first presence of neighbor in live soil vs. removal of neighbors in live soil and then live soil with neighbors removed vs. sterilized soil. The effect of soil origin and seed origin on seed production was tested both for the full and for the split databases. All analyses were carried out using the statistical software IBM SPSS Statistics 19 (IBM, Armonk, New York, USA).

\section{RESULTS}

\section{Field experiment}

There was no overall home-site advantage for any of the species. However, soil and neighbor effects as well as their interactions showed a complex pattern of relative importance for plant performance. Seed production tended to be greater in the $M$ site regardless of seed origin, but this was statistically significant only for $B i$. didyma (Table 1, Fig. 1). Neighbors consistently reduced seed production of all species (Table 1, Fig. 1) irrespective of site (no significant site $\times$ neighbor interaction; Table 1) or seed origin (no significant seed origin $\times$ neighbor interaction; Table 1). However, a significant soil origin $\times$ neighbor interaction for $\mathrm{Br}$. distachyon and $S$. capensis, pointed to a larger negative neighbor effect in $\mathrm{M}$ soil (Appendix $\mathrm{C}$ : Table $\mathrm{C} 1$, Fig. C1). All species performed significantly better in SA soil (Table 1, Fig. 1), regardless of site. Because of extremely low survival in the field, data of Urospermum picroides were excluded from the analyses.

\section{Greenhouse experiment}

Consistent with the field experiment, the presence of neighbors had a highly negative effect on seed production of all species (Table 2; Fig. 2) regardless of seed origin. Furthermore, Br. distachyon and $S$. capensis had significant soil origin $\times$ neighbor interactions (Appendix C: Table C1, Fig. C1). 
TABLE 1. Statistical results for number of seeds produced by Biscutella didyma, Brachypodium distachyon, and Stipa capensis in the field.

\begin{tabular}{|c|c|c|c|c|c|c|}
\hline \multirow[b]{2}{*}{ Effects } & \multicolumn{2}{|c|}{ Bi. didyma } & \multicolumn{2}{|c|}{ Br. distachyon } & \multicolumn{2}{|c|}{ S. capensis } \\
\hline & df & $P$ & df & $P$ & $\mathrm{df}$ & $P$ \\
\hline Site & 1 & $<0.001$ & 1 & 0.449 & 1 & 0.090 \\
\hline Neighbors & 1 & 0.033 & 1 & $<\mathbf{0 . 0 0 1}$ & 1 & 0.005 \\
\hline Seed origin & 1 & 0.311 & 1 & 0.763 & 1 & 0.418 \\
\hline Soil origin & 1 & 0.002 & 1 & $<\mathbf{0 . 0 0 1}$ & 1 & 0.023 \\
\hline Site $\times$ neighbor & 1 & 0.658 & & 0.532 & 1 & 0.557 \\
\hline Site $\times$ seed origin & 1 & 0.717 & 1 & 0.969 & 1 & 0.794 \\
\hline Site $\times$ soil origin & 1 & 0.378 & 1 & 0.407 & 1 & 0.077 \\
\hline Neighbors $\times$ seed origin & 1 & 0.259 & 1 & 0.385 & 1 & 0.618 \\
\hline Neighbors $\times$ soil origin & 1 & 0.226 & 1 & 0.037 & 1 & 0.038 \\
\hline Seed origin $\times$ soil origin & 1 & 0.528 & 1 & 0.687 & 1 & 0.753 \\
\hline Site $\times$ neighbors $\times$ seed origin & 1 & 0.571 & 1 & 0.495 & 1 & 0.754 \\
\hline Site $\times$ neighbors $\times$ soil origin & 1 & 0.439 & 1 & 0.814 & 1 & 0.493 \\
\hline Site $\times$ seed origin $\times$ soil origin & 1 & 0.362 & 1 & 0.461 & 1 & 0.506 \\
\hline Neighbors $\times$ seed origin $\times$ soil origin & 1 & 0.711 & 1 & 0.861 & 1 & 0.384 \\
\hline Site $\times$ neighbors $\times$ seed origin $\times$ soil origin & 1 & 0.464 & 1 & 0.598 & 1 & 0.228 \\
\hline
\end{tabular}

Notes: Generalized linear models with Poisson distribution and log link function were applied to the full database. Significant results $(P<0.05)$ are reported in boldface type.
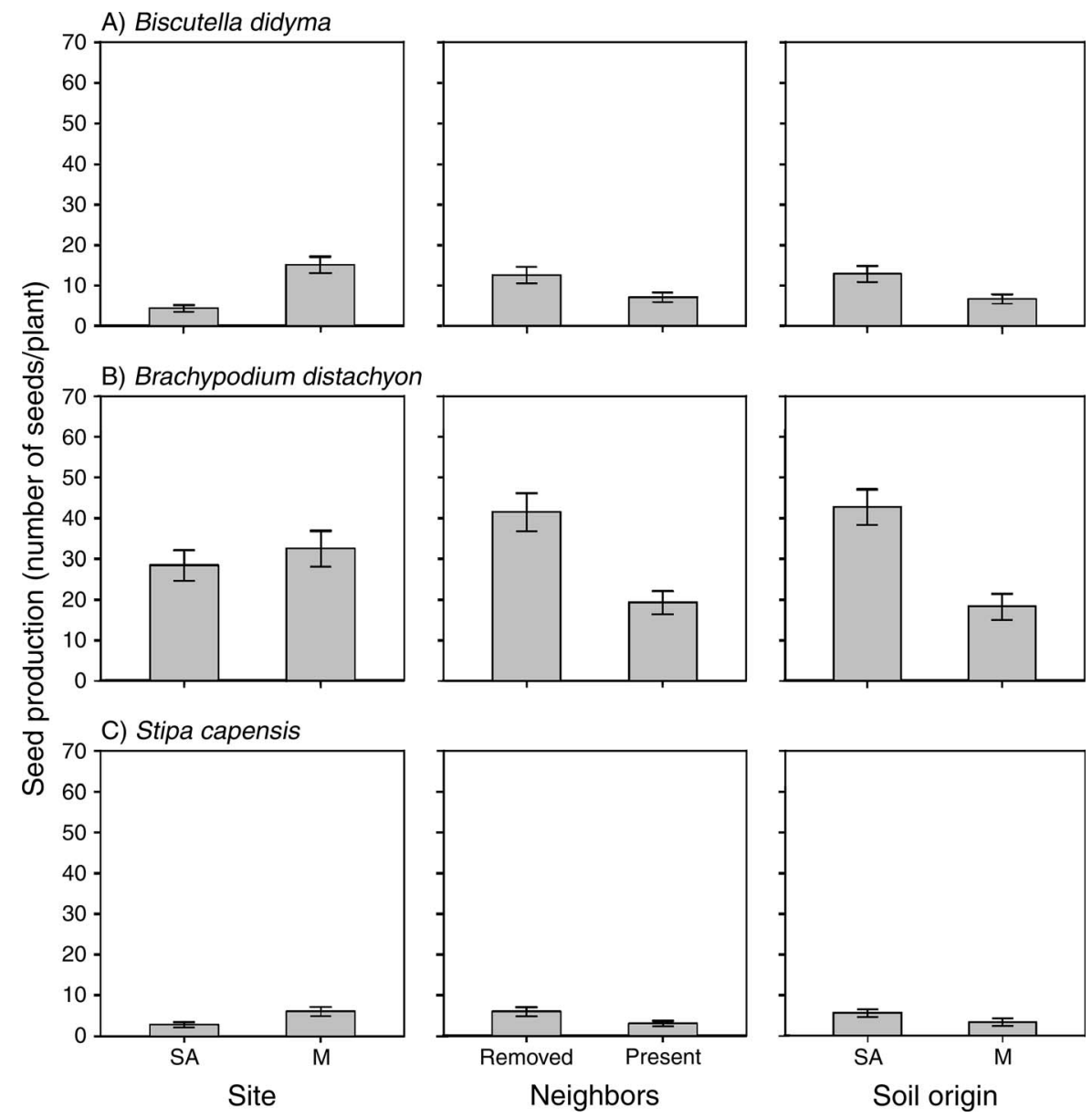

FIG. 1. Seed production (mean $\pm \mathrm{SE}$ ) in response to site, neighbors, and soil origin. The three target species grown in the field are indicated on each row; the independent variables correspond to each column. SA indicates semiarid soil origin or site and M indicates Mediterranean soil origin or site. 
TABLE 2. Statistical results for number of seeds produced by Bi. didyma, Br. distachyon, S. capensis, and Urospermum picroides in the greenhouse experiment.

\begin{tabular}{|c|c|c|c|c|c|c|c|c|}
\hline \multirow[b]{2}{*}{ Effects } & \multicolumn{2}{|c|}{ Bi. didyma } & \multicolumn{2}{|c|}{ Br. distachyon } & \multicolumn{2}{|c|}{ S. capensis } & \multicolumn{2}{|c|}{$U \cdot$ picroides } \\
\hline & $\mathrm{df}$ & $P$ & $\mathrm{df}$ & $P$ & $\mathrm{df}$ & $P$ & df & $P$ \\
\hline \multicolumn{9}{|l|}{ Full database } \\
\hline Soil origin & 1 & 0.012 & 1 & 0.870 & 1 & 0.287 & 1 & 0.023 \\
\hline Seed origin & 1 & 0.959 & 1 & 0.526 & 1 & 0.835 & 1 & 0.654 \\
\hline Community & 2 & $<0.001$ & 2 & $<\mathbf{0 . 0 0 1}$ & 2 & $<\mathbf{0 . 0 0 1}$ & 2 & $<0.001$ \\
\hline Soil origin $\times$ seed origin & 1 & 0.728 & 1 & 0.928 & 1 & 0.882 & 1 & 0.247 \\
\hline Soil origin $\times$ community & 2 & 0.102 & 2 & 0.005 & 2 & 0.066 & 2 & 0.500 \\
\hline Seed origin $\times$ community & 2 & 0.224 & 2 & 0.735 & 2 & 0.821 & 2 & 0.647 \\
\hline Soil origin $\times$ seed origin $\times$ community & 2 & 0.479 & 2 & 0.944 & 2 & 0.820 & 2 & 0.079 \\
\hline \multicolumn{9}{|l|}{ Neighbors vs. neighbors removal } \\
\hline Soil origin & 1 & $<\mathbf{0 . 0 0 1}$ & 1 & 0.444 & 1 & 0.236 & 1 & 0.064 \\
\hline Seed origin & 1 & 0.610 & 1 & 0.745 & 1 & 0.734 & 1 & 0.716 \\
\hline Neighbors & 1 & $<\mathbf{0 . 0 0 1}$ & 1 & $<\mathbf{0 . 0 0 1}$ & 1 & $<\mathbf{0 . 0 0 1}$ & 1 & $<0.001$ \\
\hline Seed origin $\times$ soil origin & 1 & 0.488 & 1 & 0.752 & 1 & 0.962 & 1 & 0.347 \\
\hline Seed origin $\times$ neighbors & 1 & 0.935 & 1 & 0.784 & 1 & 0.552 & 1 & 0.710 \\
\hline Soil origin $\times$ neighbors & 1 & 0.465 & 1 & $<\mathbf{0 . 0 0 1}$ & 1 & 0.015 & 1 & 0.584 \\
\hline Seed origin $\times$ soil origin $\mathrm{x}$ neighbors & 1 & 0.842 & 1 & 0.777 & 1 & 0.577 & 1 & 0.154 \\
\hline \multicolumn{9}{|l|}{ Sterilized vs. live soil } \\
\hline Soil origin & 1 & 0.001 & 1 & 0.015 & 1 & 0.122 & 1 & $<\mathbf{0 . 0 0 1}$ \\
\hline Seed origin & 1 & 0.509 & 1 & 0.470 & 1 & 0.828 & 1 & 0.181 \\
\hline Sterilization & 1 & 0.017 & 1 & $<0.001$ & 1 & 0.131 & 1 & \\
\hline Seed origin $\times$ soil origin & 1 & 0.581 & 1 & 0.872 & 1 & 0.386 & 1 & $<0.001$ \\
\hline Seed origin $\times$ sterilization & 1 & 0.159 & 1 & 0.504 & 1 & 0.812 & 1 & \\
\hline Soil origin $\times$ sterilization & 1 & 0.103 & 1 & 0.196 & 1 & 0.485 & 1 & \\
\hline Seed origin $\times$ soil origin $\times$ sterilization & 1 & 0.312 & 1 & 0.844 & 1 & 0.965 & 1 & \\
\hline
\end{tabular}

Notes: Generalized linear models with Poisson distribution and log link function were applied to the full database, where the community treatment refers to the combination of soil treatments (i.e., sterilized vs. live soil) and neighbor treatments (i.e., presence vs. removal), and subsequently to the database split according to soil and neighbors. Significant results $(P<0.05)$ are reported in boldface type. Note that no individuals of the species $U$. picroides survived in sterilized soil. Consequently, we did not have any data to perform our analyses regarding the effect of sterilization treatment on seed production in $U$. picroides.

The effect of soil origin on plant performance instead varied among species (Table 2, Fig. 2). Bi. didyma produced more seeds in SA soil, whereas the other three species showed no significant difference between soil origins when looking at the full database, and a higher seed production in $\mathrm{M}$ soil when looking at the subset comparing live vs. sterilized soil. A significant two-way seed origin $\times$ soil origin interaction was found in $U$. picroides when comparing live vs. sterilized soil, showing a preference for $M$ soil. Soil sterilization had a significant effect on seed production, but the strength and direction of the effect varied considerably among species (Table 2; Fig. 2). Bi. didyma showed higher seed production in sterilized soil, whereas $\mathrm{Br}$. distachyon produced more seeds in live than in sterilized soil, and in the extreme case of $U$. picroides no individual survived until seed production in sterilized soil. Instead, $S$. capensis did not show any significant difference in seed production between treatments. The effect of sterilization did not vary among soil or seed origin (no significant soil origin $x$ sterilization or seed origin $x$ sterilization interactions).

\section{DisCUSSION}

Our overall results demonstrate that for determining the potential of plants to adapt to climate change, it is crucial to dissect the various abiotic and biotic factors that covary with climate. Here, we have chosen to focus on climatically very different sites, with the main aim of establishing the relative importance of site, seed origin, soil conditions, and neighbors on plant performance. We showed that both soil and neighbors had substantially stronger effects on plant performance than site, suggesting that the effect of site (i.e., climate) was overridden by biotic interactions. The seed origin $\times$ site interaction, which would have been the main factor tested in a classical reciprocal transplant approach (Kawecki and Ebert 2004), was never significant in any of the target species. Hence, with standard reciprocal transplants that ignore plant-plant and plant-soil-biota interactions, our overall conclusions about local adaptation and the potential response to climate change would have been entirely different. In that respect, our study showed that neglecting the effect of soil properties, soil biota and neighbors, may yield highly misleading and possibly too optimistic conclusions about adaptive plant response to climate change.

In the following, we discuss our findings with respect to the initial hypotheses. We expected to find local adaptation to home site conditions. Instead, the effect of site alone was barely significant in the field except for a general preference for the wetter Mediterranean climate. Because the difference in precipitation between the two sites is far more than the year-to-year variation naturally 
A) Biscutella didyma

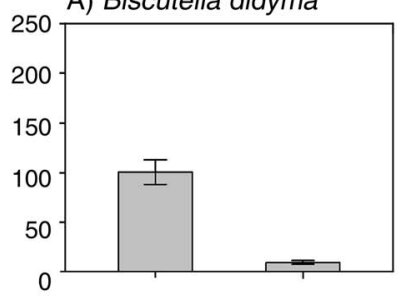

B) Brachypodium distachyon

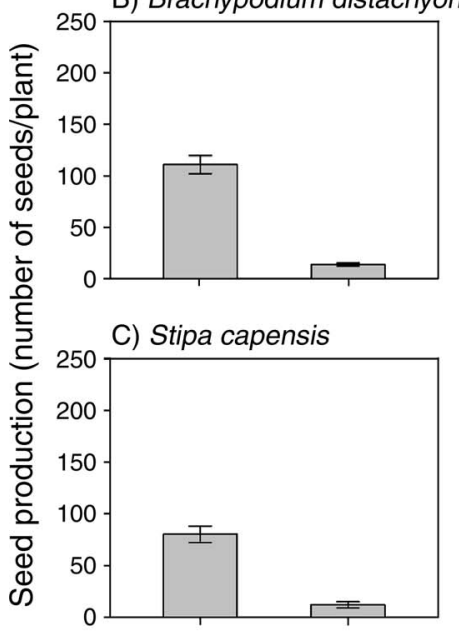

D) Urospermum picroides

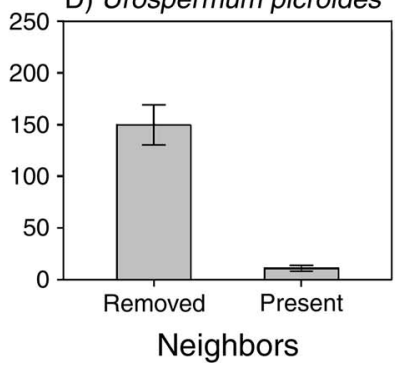

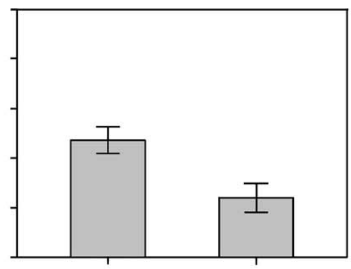
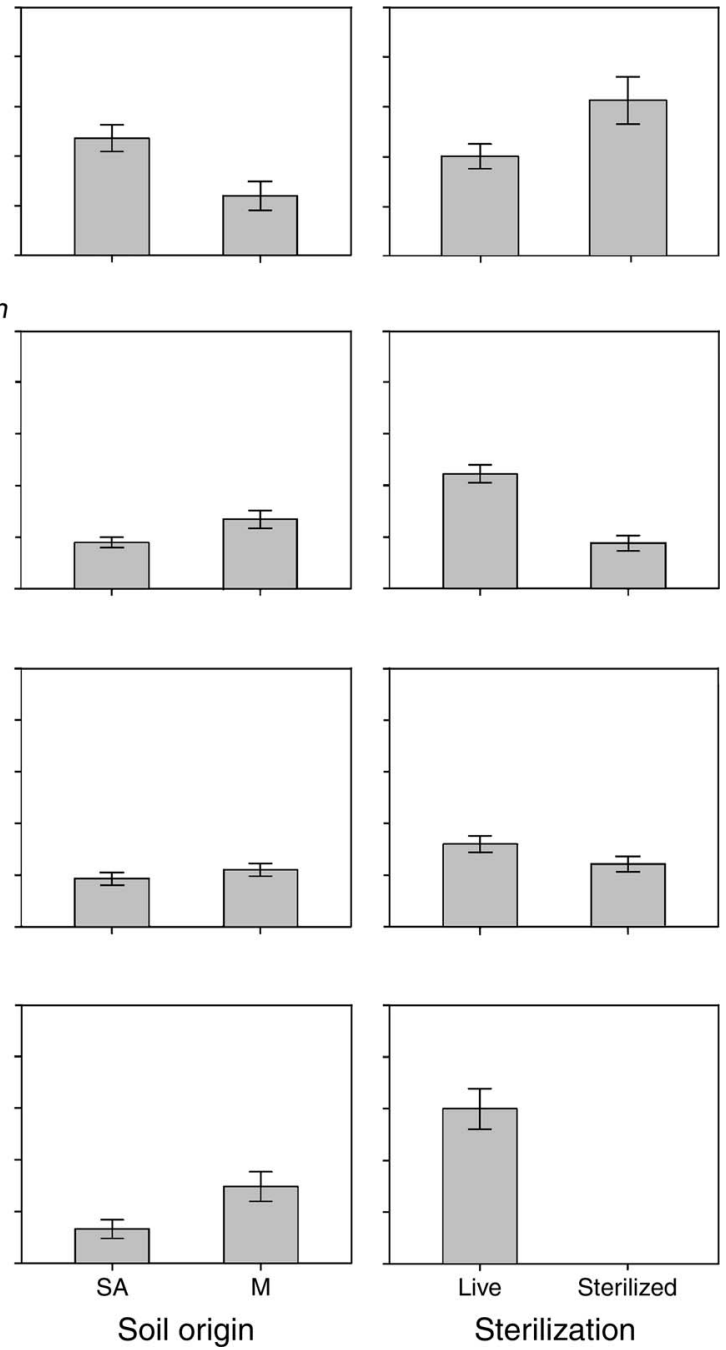

FIG. 2. Seed production (mean $\pm \mathrm{SE}$ ) in response to soil origins (results relative to full database), neighbors, and sterilization (results relative to split database). The four target species grown in the greenhouse are indicated on each row; the independent variables correspond to each column. SA indicates semiarid soil origin and M Mediterranean soil origin.

experienced at each site, the lack of any significant interaction between seed origin and site is suggestive of no local adaptation to climate sensu strictu. However, the relatively weak effect of rainfall on seed production could indicate an adaptation to the naturally large yearto-year rainfall variation in the region, putting forward adaptation to environmental heterogeneity rather than to mean climatic conditions (Etterson 2004). Alternatively, the slight preference for the Mediterranean climate might be simply the consequence of more water availability at that site. In that case, the stronger response of Biscutella didyma (the only species experiencing a significantly higher seed production) could be due to poor resistance to drought previously observed in non-mycorrhizal families such as Crucifers (Augé 2001). On the other hand, grasses were shown to be relatively resistant to drought in a previous study in this system
(Metz et al. 2010) which corroborates the findings of our field experiment.

In contrast to the relatively weak effect of site, there was a consistently negative effect of neighbors on plant performance both in the field and in the greenhouse. Competition always strongly reduced seed production, regardless of site, seed origin and species identity. However, our hypothesis that the effect of competition would be greater at the wetter site was not supported. Furthermore, the lack of a significant seed origin $\times$ neighbor interaction suggests no differential adaptation of seed origins to competition. This contradicts previous studies in the same region which showed more distinct negative effects of neighbor presence on seed production in wetter climates (Schiffers and Tielbörger 2006) and a higher competitive ability in Mediterranean seed origins (Liancourt and Tielbörger 2011). However, the interac- 


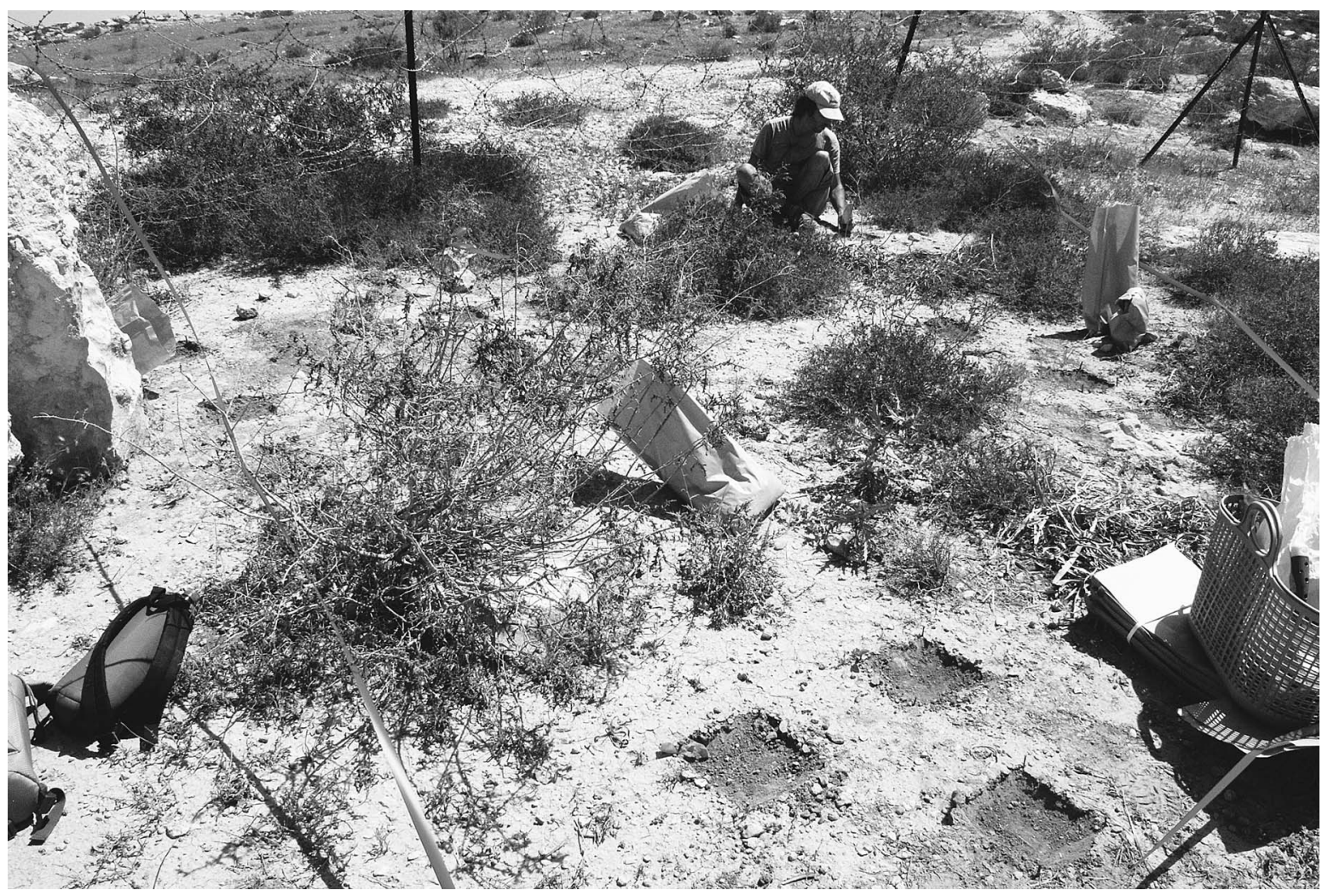

Plate 1. Setting up of one of our blocks in the field at the semiarid site in Israel, July 2010. The plots (marked with tape on the corner) were excavated avoiding rocks and patches under shrubs. This part of the fieldwork was carried out during the dry season, when the winter annuals are stored as seeds in the seed bank and the landscape is dominated by small shrubs. Photo credit: S. Tomiolo.

tion between soil origin and neighbors indicated a higher competitive release in Mediterranean soils. This effect, likely caused by the different initial density of the seed bank among soil origins (four times higher in Mediterranean soil; Appendix C: Table C1) might point at enhanced competition intensity in Mediterranean communities. Although this interpretation would be easier to verify when we had controlled for the density and identity of neighbors, we opted for using the natural seed bank rather than creating a standard artificial community in order to avoid potential bias to our results. Overall, our results might actually support our assumption about competition being more important in determining fitness under favorable conditions. This is in line with the assumption that environmental favorability and competition intensity are positively correlated (Grime 1977, Callaway et al. 2002, He et al. 2013).

Our hypothesis that plants from productive environments perform better in foreign soil was only partly confirmed. In the field, we found a generally higher performance in semiarid soil origin rather than an ecotype-specific soil preference. However, we observed the opposite pattern in the greenhouse, where only $B i$. didyma showed a preference for semiarid soil and all other species performed better in Mediterranean soil.
We believe that this difference can be explained by the fact that we excluded water limitation in the greenhouse. As a consequence, without the filter of abiotic stress, Mediterranean soils did not exhibit the same negative effects as in the field. The results from the field experiment might be explained by differences in both abiotic and biotic factors across soil origins. Mediterranean soil had a high clay content and fine grained texture, which provides ideal conditions for plant growth if water is not limiting such as in the greenhouse (Salter and Williams 1965), but is highly unfavorable under water stress, e.g., in the field. On the other hand, semiarid soil with a higher proportion of silt allows for more available water for plants even during droughts (Salter and Williams 1965). Furthermore, as shown by previous studies, high stress environments are more likely to exhibit positive plant-soil-biota interactions (Reynolds et al. 2003) as opposed to low-stress environments, characterized by high productivity, elevated plant density, and high occurrence of negative interactions between plants and soil organisms (Kardol et al. 2007, Kulmatiski et al. 2012). As such, the combination of these two factors could provide a solid explanation for the behavior of plants in the field, characterized by a generally better performance in the 
soil with potentially higher water content and less negative plant-soil-biota interactions.

The contrasting findings observed in the greenhouse and in the field might be explained by the different response of plants to soil biota. Our initial hypothesis assumed a negative effect of soil biota on plant performance in productive environments as opposed to semiarid environments where we expected positive effects. The sterilization treatment allowed for separating the role of soil biota from soil abiotic properties, and revealed species-specific interactions of plants with the soil community (Gundale et al. 2014). Interestingly, the only species that benefitted from soil sterilization (Bi. didyma) belongs to a non-mycorrhizal family (Newman and Reddell 1987), and therefore, it likely experienced mostly negative interactions with soil biota in live soil. We are well aware that soil sterilization may also increase nutrient availability (Troelstra et al. 2001) and that target species might show differential response to sterilization, but the fact that not all plant species responded similarly to soil sterilization strongly suggests that also biotic interactions, independent of altered nutrient supply, may have been involved in causing plant responses. Release from enemies through soil sterilization, therefore, offers a parsimonious explanation for the increased performance of Bi. didyma in sterilized soil. The idea that $B i$. didyma might have benefitted from release of negative soil biota impacts is also supported by the higher performance of this species in semiarid soil origin where negative plant-soil-biota interactions are less prominent (Reynolds et al. 2003) than in Mediterranean soil. Interestingly, the other three species showed a consistently opposite response to manipulation of soil biota. Brachypodium distachyon, Urospermum picroides, and Stipa capensis are mycorrhizal species, and they produced more seeds in live soil, which could be explained by the presence of symbionts. This interpretation is supported by the observation that when grown in live soil, these species preferred Mediterranean soil origin, i.e., the soil type that most likely contains a higher proportion of mycorrhizal fungi that could offset negative plant-soil-biota interactions (Azcón-Aguilar and Barea 1997). Although mycorrhizal infection and finer controls on the effect of sterilization on soil abiotic properties might be tested further, the highly significant effect of sterilization and soil origin on seed production, and the intriguingly strong and consistent difference in response across mycorrhizal and non-mycorrhizal species support our proposed explanation. This also opens up an interesting avenue for future multi-species studies that could explicitly replicate mycorrhizal and non-mycorrizal species to test the validity of our interpretation.

In conclusion, regional climate models suggest a decrease in average annual precipitation of approximately $25 \%$ over the next 50-80 years (Smiatek et al. 2011), a range that is within the variation naturally experienced by the species, but the response of plants to the predicted climate change may be limited (Tielbörger et al. 2014). Our results reveal complex effects of climate on biotic interactions, which affect species performance indirectly. Under high water stress, abiotic soil properties were most important and overrode species-specific interactions between plants and soil biota. Vice-versa, under low stress conditions, soil biota prevailed in influencing plant performance as shown by the effect of sterilization and by the preference for Mediterranean soil in the greenhouse. This implies that under drier conditions, semiarid soils could provide a better substrate for plant growth, whereas under higher rainfall, Mediterranean soil would provide better conditions for mycorrhizal species. Our results suggest that as soil properties change, not all species will be able to adapt, and some will either shift distribution or go extinct.

Therefore, future studies that aim for reliable predictions about response of plant species to climate change should test these results under a larger variety of climatic conditions, also including independent replications within site conditions, and integrate evolutionary processes (Jump and Penuelas 2005, Schiffers et al. 2013, Thuiller et al. 2013) with biotic interactions.

\section{ACKNOWLEDGMENTS}

We thank Jaime Kigel and Marcelo Sternberg for logistic support; Merav Seifan, Michal Gruntman, and Mark Bilton for comments on an early draft of the manuscript, and Steven Allison and two anonymous reviewers for helpful suggestions. The Hebrew University of Jerusalem (Rehovot) kindly provided material for fieldwork. This study is part of the GLOWA Jordan River Project funded by the German Ministry of Education and Research (BMBF).

\section{Literature Cited}

Alon, A., and Y. Steinberger. 1999. Response of the soil microbial biomass and nematode population to a wetting event in nitrogen-amended Negev desert plots. Biology and Fertility of Soils 30:147-152.

Ariza, C., and K. Tielbörger. 2011. An evolutionary approach to studying the relative importance of plant-plant interactions along environmental gradients. Functional Ecology 25: 932-942.

Augé, R. M. 2001. Water relations, drought and vesiculararbuscular mycorrhizal symbiosis. Mycorrhiza 11:3-42.

Azcón-Aguilar, C., and J. M. Barea. 1997. Arbuscular mycorrhizas and biological control of soil-borne plant pathogens - an overview of the mechanisms involved. Mycorrhiza 6:457-464.

Bertness, M. D., and R. Callaway. 1994. Positive interactions in communities. Trends in Ecology \& Evolution 9:191-193.

Brooker, R. W., and T. V. Callaghan. 1998. The balance between positive and negative plant interactions and its relationship to environmental gradients: a model. Oikos 81: 196-207.

Callaway, R. M., et al. 2002. Positive interactions among alpine plants increase with stress. Nature 417:844-848.

Callaway, R. M., and L. R. Walker. 1997. Competition and facilitation: a synthetic approach to interactions in plant communities. Ecology 78:1958-1965.

Casper, B. B., and J. P. Castelli. 2007. Evaluating plant-soil feedback together with competition in a serpentine grassland. Ecology Letters 10:394-400. 
Davis, M. B., R. G. Shaw, and J. R. Etterson. 2005. Evolutionary responses to changing climate. Ecology 86: 1704-1714.

De Long, J. R., P. Kardol, M. K. Sundqvist, G. F. Veen, and D. A. Wardle. 2014. Plant growth response to direct and indirect temperature effects varies by vegetation type and elevation in a subarctic tundra. Oikos, in press.

Etterson, J. R. 2004. Evolutionary potential of Chamaecrista fasciculata in relation to climate change. 1. Clinal patterns of selection along an environmental gradient in the great plains. Evolution 58:1446-1458.

Feinbrun-Dothan, N. 1986. Flora Palestina. Israel Academy of Sciences and Humanities, Jerusalem, Israel.

Galen, C., J. S. Shore, and H. Deyoe. 1991. Ecotypic divergence in alpine Polemonium viscosum - genetic structure, quantitative variation, and local adaptation. Evolution 45:1218-1228.

Galloway, L. F., and C. B. Fenster. 2000. Population differentiation in an annual legume: local adaptation. Evolution 54:1173-1181.

Gilman, S. E., M. C. Urban, J. Tewksbury, G. W. Gilchrist, and R. D. Holt. 2010. A framework for community interactions under climate change. Trends in Ecology \& Evolution 25:325-331.

Grime, J. 1977. Evidence for the existence of three primary strategies in plants and its relevance to ecological and evolutionary theory. American Naturalist 111:1169-1194.

Gundale, M. J., P. Kardol, M. C. Nilsson, U. Nilsson, R. W. Lucas, and D. A. Wardle. 2014. Interactions with soil biota shift from negative to positive when a tree species is moved outside its native range. New Phytologist 202:415-421.

He, Q., M. D. Bertness, and A. H. Altieri. 2013. Global shifts towards positive species interactions with increasing environmental stress. Ecology Letters 16:695-706.

Holzapfel, C., K. Tielbörger, H. A. Parag, J. Kigel, and M. Sternberg. 2006. Annual plant-shrub interactions along an aridity gradient. Basic and Applied Ecology 7:268-279.

Jump, A. S., and J. Penuelas. 2005. Running to stand still: adaptation and the response of plants to rapid climate change. Ecology Letters 8:1010-1020.

Kardol, P., N. J. Cornips, M. M. L. van Kempen, J. M. T. Bakx-Schotman, and W. H. van der Putten. 2007. Microbemediated plant-soil feedback causes historical contingency effects in plant community assembly. Ecological Monographs 77:147-162.

Kawecki, T. J., and D. Ebert. 2004. Conceptual issues in local adaptation. Ecology Letters 7:1225-1241.

Klanderud, K. 2005. Climate change effects on species interactions in an alpine plant community. Journal of Ecology 93:127-137.

Klironomos, J. N. 2003. Variation in plant response to native and exotic arbuscular mycorrhizal fungi. Ecology 84:22922301.

Kulmatiski, A., K. H. Beard, and J. Heavilin. 2012. Plant-soil feedbacks provide an additional explanation for diversityproductivity relationships. Proceedings of the Royal Society B 279:3020-3026.

Lau, J. A., and J. T. Lennon. 2011. Evolutionary ecology of plant-microbe interactions: soil microbial structure alters selection on plant traits. New Phytologist 192:215-224.

Lavergne, S., N. Mouquet, W. Thuiller, and O. Ronce. 2010. Biodiversity and climate change: integrating evolutionary and ecological responses of species and communities. Annual Review of Ecology, Evolution, and Systematics 41:321-350.

Liancourt, P., and K. Tielbörger. 2011. Ecotypic differentiation determines the outcome of positive interactions in a dryland annual plant species. Perspectives in Plant Ecology, Evolution and Systematics 13:259-264.
Linhart, Y. B., and M. C. Grant. 1996. Evolutionary significance of local genetic differentiation in plants. Annual Review of Ecology and Systematics 27:237-277.

Link, S. O., J. L. Smith, J. J. Halvorson, and H. Bolton. 2003. A reciprocal transplant experiment within a climatic gradient in a semiarid shrub-steppe ecosystem: effects on bunchgrass growth and reproduction, soil carbon, and soil nitrogen. Global Change Biology 9:1097-1105.

Macel, M., et al. 2007. Climate vs. soil factors in local adaptation of two common plant species. Ecology 88:424433.

Maestre, F. T., R. M. Callaway, F. Valladares, and C. J. Lortie. 2009. Refining the stress-gradient hypothesis for competition and facilitation in plant communities. Journal of Ecology 97: 199-205.

McNamara, N. P., H. I. J. Black, N. A. Beresford, and N. R. Parekh. 2003. Effects of acute gamma irradiation on chemical, physical and biological properties of soils. Applied Soil Ecology 24:117-132.

Metz, J., P. Liancourt, J. Kigel, D. Harel, M. Sternberg, and K. Tielbörger. 2010. Plant survival in relation to seed size along environmental gradients: a long-term study from semi-arid and Mediterranean annual plant communities. Journal of Ecology 98:697-704.

Neuhauser, C., and J. E. Fargione. 2004. A mutualismparasitism continuum model and its application to plantmycorrhizae interactions. Ecological Modelling 177:337-352.

Newman, E., and P. Reddell. 1987. The distribution of mycorrhizas among families of vascular plants. New Phytologist 106:745-751.

Noy-Meir, I. 1973. Desert ecosystems environment and producers. Annual Review of Ecology and Systematics 4: $25-51$.

Oren, A., and Y. Steinberger. 2008. Catabolic profiles of soil fungal communities along a geographic climatic gradient in Israel. Soil Biology and Biochemistry 40:2578-2587.

Ortegon-Campos, I., L. Abdala-Roberts, V. Parra-Tabla, J. C. Cervera, D. Marrufo-Zapata, and C. M. Herrera. 2012. Influence of multiple factors on plant local adaptation: soil type and folivore effects in Ruellia nudiflora (Acanthaceae). Evolutionary Ecology 26:545-558.

Petrů, M., and K. Tielbörger. 2008. Germination behaviour of annual plants under changing climatic conditions: separating local and regional environmental effects. Oecologia 155:717728.

Petrů, M., K. Tielbörger, R. Belkin, M. Sternberg, and F. Jeltsch. 2006. Life history variation in an annual plant under two opposing environmental constraints along an aridity gradient. Ecography 29:66-74.

Reynolds, H. L., A. Packer, J. D. Bever, and K. Clay. 2003. Grassroots ecology: plant-microbe-soil interactions as drivers of plant community structure and dynamics. Ecology 84 : 2281-2291.

Sala, O. E., F. S. Chapin, III, J. J. Armesto, E. Berlow, J. Bloomfield, R. Dirzo, E. Huber-Sanwald, L. F. Huenneke, R. B. Jackson, and A. Kinzig. 2000. Global biodiversity scenarios for the year 2100. Science 287:1770-1774.

Salter, P., and J. Williams. 1965. The influence of texture on the moisture characteristics of soils. Journal of Soil Science 16:115.

Saxton, K. E., W. J. Rawls, J. S. Romberger, and R. I. Papendick. 1986. Estimating generalized soil-water characteristics from texture. Soil Science Society of America Journal 54:1031-1036.

Schiffers, K., E. C. Bourne, S. Lavergne, W. Thuiller, and J. M. Travis. 2013. Limited evolutionary rescue of locally adapted populations facing climate change. Philosophical Transactions of the Royal Society B 368:20120083. 
Schiffers, K., and K. Tielbörger. 2006. Ontogenetic shifts in interactions among annual plants. Journal of Ecology 94: 336-341.

Schweiger, O., et al. 2010. Multiple stressors on biotic interactions: how climate change and alien species interact to affect pollination. Biological Reviews 85:777-795.

Schweitzer, J. A., J. K. Bailey, D. G. Fischer, C. J. LeRoy, E. V. Lonsdorf, T. G. Whitham, and S. C. Hart. 2008. Plant-soilmicroorganism interactions: heritable relationship between plant genotype and associated soil microorganisms. Ecology $89: 773-781$

Shannon, S., S. L. Flory, and H. Reynolds. 2012. Competitive context alters plant-soil feedback in an experimental woodland community. Oecologia 169:235-243.

Siewert, W., and K. Tielbörger. 2010. Dispersal-dormancy relationships in annual plants: putting model predictions to the test. American Naturalist 176:490-500.

Smiatek, G., H. Kunstmann, and A. Heckl. 2011. Highresolution climate change simulations for the Jordan River area. Journal of Geophysical Research-Atmospheres 116.

Sternberg, M., C. Holzapfel, K. Tielbörger, P. Sarah, J. Kigel, H. Lavee, A. Fleischer, F. Jeltsch, and M. Köchy. 2011. The use and misuse of climatic gradients for evaluating climate impact on dryland ecosystems - an example for the solution of conceptual problems. Pages 361-374 in M. Veste, A. Linstädter, and S. W. Breckle, editors. Gradients in drylands: linking patterns and processes and their consequences for biodiversity. Springer, New York, New York, USA.

Sundqvist, M. K., N. J. Sanders, and D. A. Wardle. 2013. Community and ecosystem responses to elevational gradients: processes, mechanisms, and insights for global change. Annual Review of Ecology, Evolution, and Systematics 44: 261-280.

Thrall, P. H., M. E. Hochberg, J. J. Burdon, and J. D. Bever. 2007. Coevolution of symbiotic mutualists and parasites in a community context. Trends in Ecology \& Evolution 22:120126.

Thuiller, W., T. Münkemüller, S. Lavergne, D. Mouillot, N. Mouquet, K. Schiffers, and D. Gravel. 2013. A road map for integrating eco-evolutionary processes into biodiversity models. Ecology Letters 16:94-105.

Tielbörger, K., M. C. Bilton, J. Metz, J. Kigel, C. Holzapfel, E. Lebrija-Trejos, I. Konsens, H. A. Parag, and M. Sternberg. 2014. Middle-Eastern plant communities tolerate nine years of drought in a multi-site climate manipulation experiment. Nature Communications 5:5102.
Tielbörger, K., A. Fleischer, L. Menzel, J. Metz, and M. Sternberg. 2010. The aesthetics of water and land: a promising concept for managing scarce water resources under climate change. Philosophical Transactions of the Royal Society A 368:5323-5337.

Tielbörger, K., M. Petru, and C. Lampei. 2012. Bet-hedging germination in annual plants: a sound empirical test of the theoretical foundations. Oikos 121:1860-1868.

Troelstra, S. R., R. Wagenaar, W. Smant, and B. A. M. Peters. 2001. Interpretation of bioassays in the study of interactions between soil organisms and plants: involvement of nutrient factors. New Phytologist 150:697-706.

Turesson, G. 1930. The selective effect of climate upon the plant species. Hereditas 14:99-152.

Tylianakis, J. M., R. K. Didham, J. Bascompte, and D. A. Wardle. 2008. Global change and species interactions in terrestrial ecosystems. Ecology Letters 11:1351-1363.

van der Putten, W. H., et al. 2009. Empirical and theoretical challenges in aboveground-belowground ecology. Oecologia 161:1-14.

van der Putten, W. H., M. Macel, and M. E. Visser. 2010. Predicting species distribution and abundance responses to climate change: why it is essential to include biotic interactions across trophic levels. Philosophical Transactions of the Royal Society B 365:2025-2034.

van der Putten, W. H., C. van Dijk, and S. R. Troelstra. 1988. Biotic soil factors affecting the growth and development of Ammophila arenaria. Oecologia 76:313-320.

Veihmeyer, F. J., and A. H. Hendrickson. 1949. Methods of measuring field capacity and permanent wilting percentage of soils. Soil Science 68:75-94.

Walther, G.-R., E. Post, P. Convey, A. Menzel, C. Parmesan, T. J. Beebee, J.-M. Fromentin, O. Hoegh-Guldberg, and F. Bairlein. 2002. Ecological responses to recent climate change. Nature 416:389-395.

Wardle, D. A., and M. Jonsson. 2013. Long-term resilience of above- and belowground ecosystem components among contrasting ecosystems. Ecology 95:1836-1849.

Weiner, J., S. Martinez, H. Muller-Scharer, P. Stoll, and B. Schmid. 1997. How important are environmental maternal effects in plants? A study with Centaurea maculosa. Journal of Ecology 85:133-142.

Zwikel, S., H. Lavee, and P. Sarah. 2007. Temporal evolution of salts in Mediterranean soils transect under different climatic conditions. Catena 70:282-295.

\section{Supplemental Material}

\section{Ecological Archives}

Appendices A-C are available online: http://dx.doi.org/10.1890/14-1445.1.sm 